\title{
Air permeability, water penetration and water absorption to specify durability of eco-efficient concrete
}

\author{
Joachim Juhart ${ }^{\mathrm{a}^{*}}$, Rok Bregar ${ }^{\mathrm{a}}$, Gheorghe Alexandru David ${ }^{\mathrm{a}}$, Markus Krüger ${ }^{\mathrm{a}}$ \\ ${ }^{a}$ Institute of Technology and Testing of Construction Materials, Graz University of Technology, Graz, Austria
}

Received: 26 February 2019 / Accepted: 19 September 2019 / Published online: 18 October 2019

(C) The Author(s) 2019. This article is published with open access and licensed under a Creative Commons Attribution 4.0 International License.

\begin{abstract}
The durability of eco-efficient, clinker reduced concrete is a key factor for its performance. In the study presented, different durability indicators of a newly developed eco-concrete composition (ECO) are tested and compared with standard normal concrete as reference (REF). The tested durability indicators are open porosity, water penetration depth, rate of water absorption by capillarity and two different methods for measuring air permeability (PermeaTORR AC device versus Testing bubble counter). The ECO mix and in particular its cementitious matrix is designed by a combined filler concept substituting Portland cement partially by carefully selected limestone fillers of different grain sizes. The approach is based on a combination of particle packing optimization techniques and the reduction of water demand to achieve a specific flowability of the paste. The cement content is below the limits of actual descriptive standards while w/c-ratio exceeds such limits. The performance of the eco-concrete in terms of workability and strength is at least equivalent to the reference normal concrete, while simultaneously the ecological impact indicators such as global warming potential and embodied energy are substantially improved. Durability indicators overall show nearly equivalent performance of ECO and REF concrete. In detail, the resulting air permeability coefficient tested with a bubble counter differs significantly from the coefficient determined by PermeaTORR, which is mainly attributed to different moisture content.
\end{abstract}

Keywords: Sustainable concrete; Eco-efficiency; Durability testing; Air permeability; Performance specification

\section{Introduction}

In times of climate change increasing attention must be directed to greenhouse gas emissions ( $\mathrm{kg} \mathrm{CO}_{2}$-equ., global warming potential, GWP) and embodied energy (or total primary energy, $\mathrm{PEt}$ ) of the most used construction material worldwide - normal concrete [1], [2]. In respect to durability of innovative, eco-efficient materials, the specification of test methods and parameters to prove their performance over their service life is of prime importance, especially as these do not comply with existing standards, such as the "ecoconcrete" presented in the paper. The consideration of both durability performance and environmental impact is the basis of sustainable concrete [4]. Such investigations were also in the focus of COST action TU 1404 'Towards the next generation of standards for service life of cement-based materials and structures' [3].

The principles of "green concrete" or "ecological concrete" were pointed out by $[1,2,4-6]$. The general approach of this study is illustrated in Figure 1 according to [7-9]. The methodology is based on the optimization of packing density and the minimization of water demand especially of the powders that represent the paste (i.e. all granular materials with a maximum grain size $<125 \mu \mathrm{m}$ ) taking into account their environmental impact. At the same time, equivalent functional performance of an eco-mix compared to normal concrete has to be considered. Cement clinker - which represents 95 wt.\% of ordinary Portland cement (PC) according to EN 197-1:2018 and is also the main constituent of Portland composite cement - is primarily responsible for GWP and PEt of the paste of normal concrete [1,2]. In an optimized paste PC with its high GWP and PEt is partly substituted by properly selected very fine micro-fillers (MF) and coarser eco-fillers (EF) that have low water demand and lower environmental impact (Table 2), [9]. Previous studies on ecological concrete [6] and ultra-high performance concrete (UHPC) [10] showed that a physical filler effect can be achieved by a size ratio of smaller particles to larger particles (i.e. cement, supplementary cementitious materials, fillers) $\left.\mathrm{d}_{\mathrm{MF}} / \mathrm{d}_{(\text {larger particle }}\right) \leq 0.33$ with an optimum reached at a ratio $\simeq$ 0.1 . MFs practically have an average particle diameter $d_{50} \ll$ $5 \mu \mathrm{m}$ in any case, which is significantly lower than for PC. In this study, MF and EF are carefully selected limestone powders. Other possible powders for an eco-optimization are dolomite, quartz, residuals or secondary cementitious materials. Secondary raw materials in particular (ground

* Corresponding author: Joachim Juhart, E-mail: joachim.juhart@tugraz.at 
granulated blast furnace slag, fly ash etc.) can be utilized according to the presented method if regionally available, but are out of the scope of this work.

normal paste eco-efficient paste

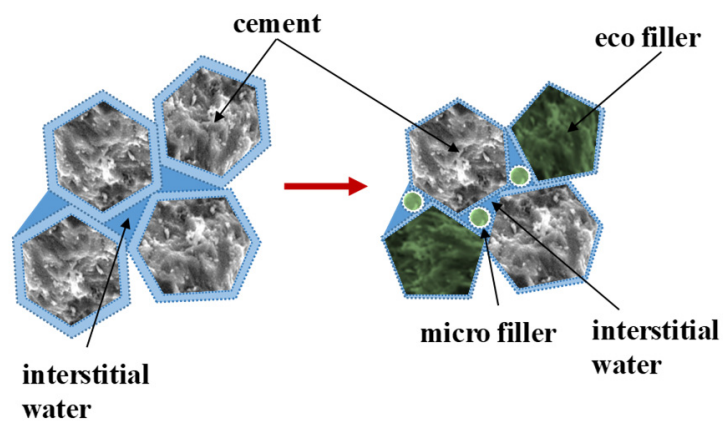

Figure 1. Optimizing paste by using combined fillers: normal paste of $\mathrm{PC}$ and water versus eco-efficient paste with $\mathrm{PC}$ and combined fillers (EF, MF). Eco-paste has enhanced packing density and lower water demand than normal paste for equal flowability as well as reduced environmental impact.

An optimized mix of $\mathrm{PC} / \mathrm{EF} / \mathrm{MF}$ according to Figure 1 requires less water for achieving a specific flowability than normal paste (mainly of PC). This is due to: (i) packing optimization, which corresponds to the physical filler effect of MFs and/or an optimized grain size distribution of all granular materials; (ii) a significant amount of EF, which has a high sensitivity to water addition and therefore lowers the water demand required for a specific flowability of a mix; (iii) addition of superplasticizers (SP). As SP have a high environmental impact (Table 2), they must be used sparingly in an ecooptimization process. With such an optimized mix it would be possible to lower the total amount of water in the mix and even the w/c-ratio (water/cement), a principle that is successfully applied for UHPC. In our case of eco-concrete, the paste-mix is more eco-efficient when PC or clinker are partly substituted with MF and EF. Such eco-pastes typically have a lower total water content in the mix, but the same or even higher w/c-ratio as pure PC-pastes as well as decreased w/pratio (water/powder-ratio) at equal flowability and at least equal strength [9].

Traditional descriptive concepts of actual standards (e.g. EN 206-1:2013 and its national applications) prescribe a minimum cement content and maximum $\mathrm{w} / \mathrm{c}$ of concrete, whereas innovative "eco-concretes" exceed these limits. Ecoefficient concretes are hampered from being introduced into practice, due to the lack of performance-oriented specifications and test methods as components of the standards. This paper thus specifies durability parameters tested on standard concrete (REF) as a reference and also a newly developed eco-concrete (ECO) and attempts to evaluate their equivalent performance.

\section{Materials and mix design}

\subsection{Materials to design the cementitious matrix}

The following properties of powder materials are crucial for a functional and environmental performance optimization of the paste, cementitious matrix respectively [9]: (i) particle size distribution (PSD) including average particle diameter $d_{50}$ (ii) packing density and (iii) water demand to reach the desired flowability associated with specific surface area (SSA) as well as (iv) environmental indicators (GWP and PEt, see Table 2 and chapter 3.3).

PSD was measured in the range of $0.45 \mu \mathrm{m}$ to $875 \mu \mathrm{m}$ (3 repetitions) with a laser diffraction particle size analyzer (Sympathec HELOS). To provide similar measurement conditions for all powders, $10 \mathrm{ml}$ of dried powders were dispersed at a pressure of 2.5 bar. For the conversion of the diffraction spectra into a volume-based particle size distribution (of idealized homogeneous spheres) the "Mietheory" was applied. The results are presented in Figure 2.

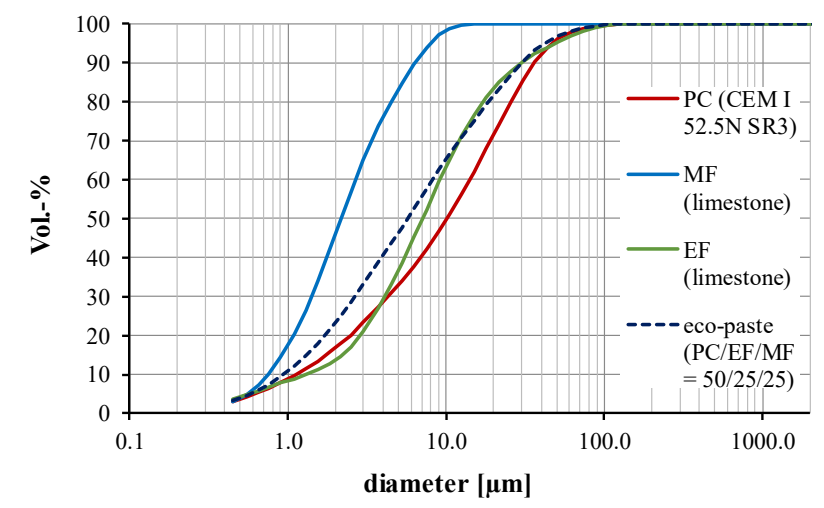

Figure 2. PSD of used powders and powder mix for the eco paste.

Parameters regarding the packing density and water demand as well as the optimum mix-ratio of $\mathrm{PC} / \mathrm{EF} / \mathrm{MF}$ were determined by a new combination of methods termed "Mi$S$ " described in detail in [9]. "Mi-S" stands for a mixing process (Mi) to measure the wet packing density $\Phi_{\text {exp }}$ of a waterpowder mix combined with a subsequent spread flow test (S). In the first step, $\Phi_{\text {exp }}$ was determined by the maximum power consumption of the mixing device during mixing and continuous water adding. The maximum power peak occurs at the maximum shear resistance and represents the watersaturation point of the powder, which is directly related to the maximum achievable wet packing density $\Phi_{\exp }$ according to Marquardt [11]. In the second step a spread flow test according to Okamura [13] was carried out. The test allows (i) the water demand at the onset of flow $\beta_{p}$ and (ii) the sensitivity to water addition $E_{p}$ of a water-powder mix to be determined. The water needed to achieve different spread flow diameters is thus measured. At several steps during water addition the volumetric $w / p$-ratio $V_{w} / V_{p}$ is plotted versus the relative spread flow area $\Gamma$ [12] so that a linear regression line can be drawn, see Figure 3 . Their parameters $\beta_{p}$ (water demand at the onset of flow) and $E_{p}$ (sensitivity of a powder to water addition) are characteristic for the material or powder mix. Table 1 shows all above mentioned properties of source materials comprised in this study (repeat determinations). It is worth noting that no superplasticizer (SP) is used during the entire procedure in our case for the material characterization. 


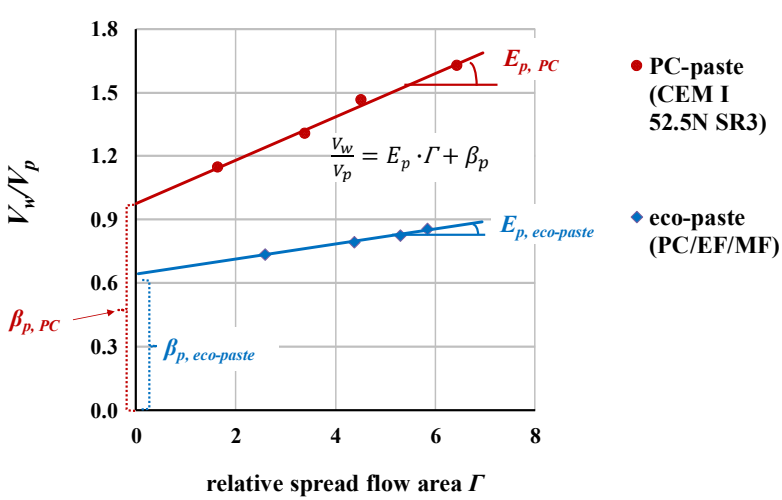

Figure 3. characteristic parameters $\beta_{p}$ (water demand at the onset of flow) and $E_{p}$ (sensitivity to water addition) of pure PC compared with eco- paste (PC/EF/MF).

The specific surface area of the powders was determined by BET-measurements as additional information (ISO 9277, device used: Micromeritics Flowsorb II 2300). Results are given in Table 1.

Table 1. Properties of granular source materials and of optimized PC/EF/MF mix

\begin{tabular}{|c|c|c|c|c|c|c|}
\hline Type & $\begin{array}{l}\rho \\
\left(\mathrm{g} / \mathrm{cm}^{3}\right)\end{array}$ & $\begin{array}{l}d_{50} \\
(\mu \mathrm{m})\end{array}$ & $\begin{array}{l}\text { SSA } \\
\left(\mathrm{m}^{2} / \mathrm{g}\right)\end{array}$ & $\begin{array}{l}\Phi_{\text {exp }} \\
(-)\end{array}$ & $\begin{array}{l}\beta_{p} \\
(-)\end{array}$ & $\begin{array}{l}E_{p} \\
(-)\end{array}$ \\
\hline $\begin{array}{l}P C \triangleq R E F \\
(C E M I 52.5 N \text { SR3) }\end{array}$ & 3.17 & 10.1 & 1.01 & 0.57 & 0.99 & 0.102 \\
\hline EF (limestone) & 2.70 & 7.1 & 0.89 & 0.60 & 0.79 & 0.047 \\
\hline MF (limestone) & 2.73 & 2.2 & 1.96 & 0.69 & 0.65 & 0.010 \\
\hline $\begin{array}{l}\text { ECO paste } \\
(\mathrm{PC} / \mathrm{EF} / \mathrm{MF}=50 / 25 / 25)\end{array}$ & 2.94 & 5.8 & 1.20 & $0.62 *$ & $0.66^{*}$ & $0.034 *$ \\
\hline
\end{tabular}

*data of one experiment

Mi-S tests were carried out with varied mix ratios of $\mathrm{PC} / \mathrm{EF} / \mathrm{MF}$ until an eco-efficient paste was found (i.e. PC/EF/MF of $50 / 25 / 25$ V.-\%) with higher $\Phi_{\text {exp }}$ and lower water demand (lower $\beta_{p}$ and $E_{p}$ ) than the reference paste of pure CEM I, see Table 1 and Figure 3 . It should be noted that the MF used possesses the ability to simultaneously increase the packing density of a mix by its physical filling effect and to enhance the flowability despite its high SSA by flow-enhancing effects similar to that of a SP [9]. Additionally, the used EF increases the flowability of the mix with PC due to its relatively low water demand $\beta_{p}$ and $E_{p}$. It can be seen from the values of $\beta_{p}$ and $E_{p}$ in Figure 3, that eco-paste needs less water to flow than pure PC-paste leading to a lower volumetric w/p-ratio at equivalent flowability. Additionally, Figure 2 shows the PSD of eco-paste's powder mix compared with that of reference PC, note the smaller $d_{50}$ and flatter slope of its PSD.

\subsection{Concrete mix design}

The concrete mix REF corresponds to the concrete used in the extended round robin test program of COST action 1404 [3]. The mix composition is given in Table 2, concrete properties are shown later (in chapter results). Both mixes REF and ECO were designed with an equal volume of paste and equal fractions of the same sand and gravel with maximum grain size of $16 \mathrm{~mm}$. Equal SP type and low SP content was used for ECO and REF to minimize SPs environmental impact. Despite a significantly higher w/c-ratio and lower w/p-ratio of ECO than REF, workability and strength were nearly the same. In addition to the reference ordinary concrete produced at TU Graz ("REF_G"), data for an ordinary concrete produced to the same formula at the University of Zagreb ("REF_Z") within the frame of a Round Robin Test program of COST action [3] is subsequently used for the comparison of durability performance.

Table 2. GWP, PEt of concrete constituents as well as concrete mix composition.

\begin{tabular}{|c|c|c|c|c|}
\hline Type & $\begin{array}{l}\text { GWP } \\
\text { (kg CO} \text {-equ./t) }\end{array}$ & $\begin{array}{l}\text { PEt } \\
(\mathrm{MJ} / \mathrm{t})\end{array}$ & $\begin{array}{l}\text { REF_G } \\
\left(\mathrm{kg} / \mathrm{m}^{3}\right)\end{array}$ & $\begin{array}{l}\text { ECO } \\
\left(\mathrm{kg} / \mathrm{m}^{3}\right)\end{array}$ \\
\hline PC CEM I 52.5 N SR3 & 831 & 4030 & 320 & 208 \\
\hline EF limestone & 25 & 717 & - & 104 \\
\hline MF limestone & 35 & 1005 & - & 104 \\
\hline sand $0 / 4 \mathrm{~mm}$, dry & 2 & 58 & 830 & 827 \\
\hline gravel $4 / 11 \mathrm{~mm}^{*}$ & 2 & 58 & 449 & 447 \\
\hline gravel $8 / 16 \mathrm{~mm}^{*}$ & 2 & 58 & 564 & 562 \\
\hline $\begin{array}{l}\mathrm{SP}(\mathrm{PCE}, \\
80 \% \text { water content) }\end{array}$ & 944 & 29150 & 1.4 & 1.4 \\
\hline added water & - & - & 172 & 126 \\
\hline effective water & - & - & 167 & 121 \\
\hline total water & - & - & 173 & 127 \\
\hline$w / c$ & - & - & 0.54 & 0.61 \\
\hline$w / p^{* *}$ & - & - & 0.54 & 0.30 \\
\hline
\end{tabular}

*fully saturated, $* *$ powder $=\mathrm{PC}+\mathrm{EF}+\mathrm{MF}$ (fines of the aggregates are not considered)

The aggregates used had significant water absorption $\left(\mathrm{WA}_{24}{ }^{-}\right.$ coefficient of sand $0 / 4$ is $0.77 w t . \%$, of gravel $4 / 11$ is 2.61 wt.\%, of gravel $8 / 16$ is 2.25 wt.\%), which had to be considered according to the guidelines of the extended round robin test of COST action 1404 [3]. The gravel was added fully watersaturated to the mix, but the sand was added in a dry state. Effective water was assumed to correspond to the added water minus absorbed water by the sand plus water content of SP, which led to an effective $w_{\text {eff }} / c$ of 0.52 of REF, 0.58 of ECO respectively and a ratio $\mathrm{w} / \mathrm{c}$ of total water to cement of $0.54,0.61$ respectively.

\section{Testing and evaluation methods}

The performance of the concrete mixes produced was evaluated in terms of: (i) functional parameters such as consistency and strength; (ii) durability indicators; (iii) environmental impact.

\subsection{Standardized functional parameters}

The flow-table spread (i.e. spread diameter on the flow-table after defined compaction according to EN 12350-5: 2009) of the mix 10 min after water addition (spread,10) was tested as well as the value $30 \mathrm{~min}$ after water addition (spread,30).

The compressive strength was tested on concrete cubes (150 
$m m, n=3$ ) according to EN 12390-3:2009 - cured for the first 24 hours in moulds covered with plastic sheet at a temperature $20-23^{\circ} \mathrm{C}$, and then stored under water until testing at an age of 1 day ("1d-strength") and 28 days ("28dstrength").

\subsection{Durability indicators}

For all durability tests, specimens were cured in moulds covered with plastic foil for 24 hours (at $20-23^{\circ} \mathrm{C}$ ) after casting, then demolded and stored under water up to 28 days, and then further prepared for each individual test as described below.

Open porosity was determined in accordance with EN 1936:2007. Cubes of $\sim 50 \mathrm{~mm}(n=4)$, cut out of a bigger specimen at an age of $28 \mathrm{~d}$, were dried at $70^{\circ} \mathrm{C}$ until constant mass, which they reached at an age of about $50 \mathrm{~d}$. In the following test their water uptake when immersed in water under partial vacuum was measured. The water uptake represents the water that accesses the open pores, which are mainly capillary pores. The open porosity was calculated by relating it to the volume of specimen.

A second parameter of the pore system is the rate of water absorption by capillarity in accordance with EN 13057:2002. Cylindrical specimens cut from drilled cores ( $\varnothing 94 \mathrm{~mm}$, height of $53 \mathrm{~mm}, \mathrm{n}=3$ ) were oven dried to constant mass (at $70^{\circ} \mathrm{C}$ ) and tested at an age of about 45 days. The specimens were placed on line-supports under water, so that its bottom surface absorbed water by capillary suction (the water level was $2 \pm 1 \mathrm{~mm}$ above bottom surface; an effect of sorption through the circumference was neglected). The specimen's water uptake was measured after $12 \mathrm{~min}, 30 \mathrm{~min}, 1 \mathrm{~h}, 2 \mathrm{~h}$, $4 \mathrm{~h}, 5 \mathrm{~h}, 24 \mathrm{~h}$ and several time steps later. A linear $\mathrm{Vt}$ relationship between water uptake and time was observed within the first $24 \mathrm{~h}$ for both concretes, REF_G and ECO. Thus the sorption coefficient was calculated according to EN 13057:2002 as the linear regression line of uptake over square root of time within $12 \mathrm{~min}$ to $24 \mathrm{~h}$ (coefficient of determination was $\mathrm{R}^{2}=0.997$ for REF_G and 0.996 for ECO).

The depth of water-penetration was tested according to EN 12390-8:2009, equivalent to Austrian standard technical rule ONR 23303:2010 [14] on water cured concrete prisms $(200 \times 200 \times 120 \mathrm{~mm}, \mathrm{n}=4)$ starting at the age of $28 \mathrm{~d}$. Pressured water was applied to one surface in 2 steps of
1.75 bar up to $3 \mathrm{~d}$ and 7.0 bar up to $14 \mathrm{~d}$ according to specifications in ONR 23303:2010 [14]. Afterwards each specimen was split and penetration depth was measured.

Air permeability was tested with two different testing procedures. The first test procedure was carried out with a "PermeaTORR AC" device [16] on concrete cubes (150 mm, $\mathrm{n}=3$ ) in accordance to SIA 262/1:2013 "air permeability on site", see Figure 1 . The specimens were stored under water to an age of $28 \mathrm{~d}$, then stored at $65 \%$ r.h. and $20^{\circ} \mathrm{C}$ up to an age of $54 \mathrm{~d}$, dried at $50^{\circ} \mathrm{C}$ for $8 \mathrm{~d}$, cooled down slowly and tested. A slightly different preconditioning was applied at Uni Zagreb (REF_Z). Specimens were stored in a curing chamber $\left(20 \pm 2^{\circ} \mathrm{C}\right.$, r.h. > 95\%) up to an age of $147 \mathrm{~d}$, dried at $50^{\circ} \mathrm{C}$ for at least $3 \mathrm{~d}$, cooled down for one day and tested. A vacuum is applied (30 to $50 \mathrm{mbar}$ ) in both concentric chambers of a vacuum cell ("active cell"), which is sealed onto the concrete surface by means of a pair of concentric soft rings. After 60 seconds, the inner chamber is disconnected from the vacuum pump and its pressure begins to rise due to air flowing through the pores in the concrete. By using the two chamber system the pressure of the outer chamber is balanced with that of the inner chamber by means of a regulator, a unidirectional flow of air into the inner chamber is ensured. The rate of increase of pressure in the inner chamber is directly linked to the coefficient of air-permeability $\mathrm{K}_{\mathrm{SIA}}$, calculated in accordance with SIA 262/1-E:2013 [15] as described in [16]. The device also displays the approximate penetration depth of the test $L$ $(\mathrm{mm})[16]$ representing the affected concrete cover depth.

For the second procedure a "Testing" bubble counter [17] was used and air permeability was tested in accordance with RILEM specification TC 116-PCD [18], see Figure 1. Cylindrical specimens were cast ( $d=150 \mathrm{~mm}$, cut to $h=50 \mathrm{~mm}, \mathrm{n}=2$ ), stored under water to an age of $28 \mathrm{~d}$, dried at $50^{\circ} \mathrm{C}$ until $56 \mathrm{~d}$, stored at $65 \%$ r.h. and $20^{\circ} \mathrm{C}$ until testing at an age of $91 \mathrm{~d}$. The specimens were sealed on their circumferences. The test device applies an overpressure to the underside of the specimen, with the result that a specific volume of inert gas (air was used) migrates over time units through the entire concrete disk to the upper side. The rate of ascent of a soap bubble at different pressure steps $(2.5,3.0,3.5$ bar) is measured. A corresponding coefficient of permeability $\mathrm{K}_{\mathrm{RIL}}$ was calculated as the mean of the three pressure steps [17].

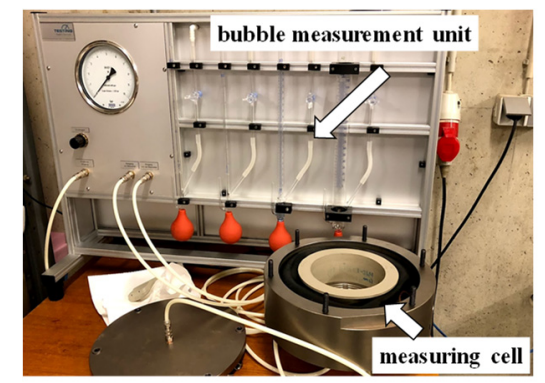

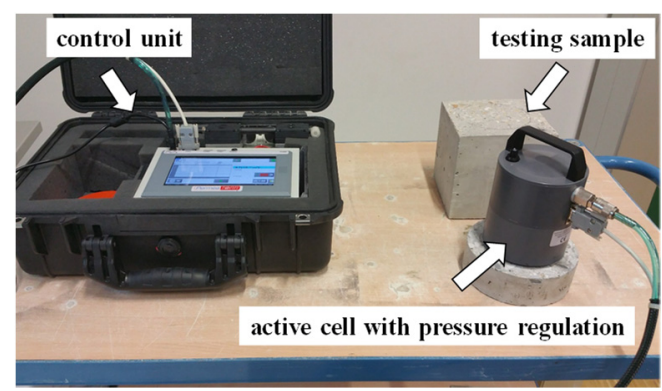

Figure 4. Test setup "PermeaTorr" (left) and "Testing" bubble counter (right). 


\subsection{Ecological impact}

The data for the environmental indicators GWP and PEt are shown in Table 2. They were taken from equivalent materials published in [7-9] calculated by the method of Life Cycle Assessment (LCA) in accordance with ISO EN 14044:2006 using SimaPro software (v. 7.3) and the ecoinvent database [19]. PC exceeds the environmental impact of finely milled stones (fillers), aggregates and secondary raw materials (GGBS, FA) by far. Superplasticizers possess very high GWP and PEt due to the energy demand of the production [20]. The ecological impact of $1 \mathrm{~m}^{3}$ fresh concrete was calculated in accordance with the values for GWP and PEt of the source materials and their fresh concrete quantities. Impacts due to production and transport were assumed identical for REF and ECO and were not taken into account.

\section{Results and Discussion}

\subsection{Workability, strength, porosity}

Table 3 shows fresh and hardened concrete properties as well as all parameters related to open porosity, water penetration depth and capillary sorption coefficient with its arithmetic means and standard deviations. In the workability context, flowable consistency of the fresh concrete directly after mixing was achieved for REF and ECO concrete (spread,10 equal to $52 \pm 2 \mathrm{~cm}$ ). However, ECO lost its consistency faster than REF, as can be seen from the values spread_30 in relation to spread_10 of both mixes. The reasons are manifold, i.e. lower w/p-ratio and higher specific particle surface, which lead to lower particle distance, SP type etc. Changing it from a highly liquefying type to a more consistency-maintaining type of SP or choosing a SP that is better adjusted to the clinker/limestone combination could compensate the effect.

The $1 \mathrm{~d}$-strength of ECO is significantly higher than that of REF, whereas the $28 \mathrm{~d}$-strength is equal, which means low $\mathrm{w} / \mathrm{p}$ and a high content of MF accelerate early age strength development [9]. This is due to multiple effects influencing the cement hydration such as increased packing density, high specific surface area providing additional nucleation sites for $\mathrm{C}-\mathrm{S}-\mathrm{H}$ growth and changed phase assemblage of the hydration products [22], [23]. This can be seen as an advantage, for example for precast applications [24].

In the context of porosity related parameters, a differentiated view is necessary. Open porosity and the sorption coefficient of REF_G are higher than that of ECO. The water penetration depth of REF_G, however, is slightly lower compared to ECO. It can be assumed that the pore size distribution and the number of connected capillary pores differ for the two mixes, but these aspects were not investigated in detail. Both REF $(15 \mathrm{~mm})$ and ECO $(18 \mathrm{~mm})$ are below limits of water penetration depth according to Austrian Standard ÖNORM B 4710-1:2018 (class XW2 limits $25 \mathrm{~mm}$ ) [21].

\subsection{Gas permeability}

The results of air permeability measurements from the two applied methods are shown in Table 4. Average values of the air permeability coefficients $\mathrm{K}_{\mathrm{RIL}}$ and $\mathrm{K}_{\mathrm{SIA}}$ are calculated as geometric means because of the logarithmic character of permeability indicators [25]. For the same reason the scatter is calculated as the standard deviation of the decimal log of $\mathrm{K}$ values $s d \log (K)$ [25]. To show the range of $K$ according to this scatter, a standard deviation factor SDF can be taken into account as $\mathrm{SDF}=10^{\wedge} \mathrm{sd} \log (\mathrm{K})$. Subsequently a range from the geometric mean divided by SDF to the geometric mean multiplied by SDF is shown in Table 4 and in Figure 5.

Table 3. Concrete properties with their standard deviations and calculated GWP and PEt

\begin{tabular}{llll}
\hline & & REF_G & ECO \\
\hline flow-table spread,10 & $\mathrm{cm}$ & $54.3 \pm 0.3$ & $50.5 \pm 1.3$ \\
flow-table spread,30 & $\mathrm{cm}$ & $43.5 \pm 0.5$ & $37.0 \pm 0.0$ \\
1 day strength & $\mathrm{MPa}$ & $11.3 \pm 1.1$ & $17.5 \pm 0.4$ \\
28 day strength & $\mathrm{MPa}$ & $55.4 \pm 2.2$ & $56.2 \pm 3.5$ \\
open porosity & $\%$ & $13.4 \pm 0.5$ & $11.5 \pm 0.4$ \\
sorption coefficient & $\mathrm{kg} / \mathrm{m}^{2} \mathrm{Vh}$ & $0.91 \pm 0.06$ & $0.69 \pm 0.04$ \\
water penetration depth & $\mathrm{mm}$ & $15.0 \pm 1.9$ & $17.8 \pm 2.0$ \\
GWP & $\mathrm{CO}-\mathrm{equ} / \mathrm{m}^{3}$ & 282 & 180 \\
PEt & $\mathrm{MJ} / \mathrm{t}$ & 1715 & 1400 \\
\hline
\end{tabular}

The air permeability coefficient $\mathrm{K}_{\mathrm{RIL}}$ of REF_G is significantly higher than that of ECO measured with the bubble counter, see Table 4 . The air permeability coefficient $K_{S I A}$, however does not confirm this. It was measured at TU Graz and Uni Zagreb with the same "PermeaTORR AC" device on REF_G and REF_Z concrete, which have the same mix composition but were manufactured in different labs with slightly different preconditioning. In the context of the geometric mean of $\mathrm{K}_{\mathrm{SIA}}$ and the range of scatter the performance difference of ECO and REF is small, with a slightly higher permeability of ECO than REF. However, according to Torrent [9] REF and ECO are classified equally into "low permeability" (very low: $\mathrm{K}_{\mathrm{SIA}} 0.001$ 0.01 E-16 m², low: $K_{\text {SIA }}$ 0.01-0.1 E-16 m², moderate: $K_{\text {SIA }} 0.1-$ $1.0 \mathrm{E}-16 \mathrm{~m}^{2}$ ).

A significant difference of the permeability coefficients tested by SIA- and RILEM-method can be observed, however, according to Table 4. Possible reasons for this are significant differences in the preconditioning of the samples and in the test procedures as described in chapter 3.2. The preconditioning led to different test ages and moisture content of the specimens. The moisture content of specimens REF_G and ECO immediately after the testing by SIA method were determined by the gravimetric method (weighing before and after a drying at $105^{\circ} \mathrm{C}$ ) resulting in $3.4 \pm 0.4$ (REF_G) and 2.6 \pm 0.1 (ECO) wt.-\%. Moisture content of specimens tested by RILEM method was not measured. But according of EN ISO 10456:2010 [26], it can be estimated to be lower than 1.6 wt.-\% (i.e. moisture content of normal concrete at $23^{\circ} \mathrm{C} / 65 \% \mathrm{RH}$, read from values of Table 4 in [26]). Consequently, the SIA-specimens moisture content was approximately twice as high as RILEM-specimens, which led to a significantly lower air permeability [27]. 
Moreover, (i) different pressure was applied (overpressure up to 3.5 bar during the RILEM test, underpressure 1 bar during the SIA test), (ii) the specimens age and therefore their hydration degree were different and (iii) the thickness and the composition of the concrete layer, which is affected by the tests were different. In the case of SIA only the cover layer corresponding to the penetration depth $L$ (i.e. 5 to $9 \mathrm{~mm}$ ) at the formworks surface of the specimen was considered, whereas in case of RILEM the through-flow was measured though a $50 \mathrm{~mm}$ thick cut specimen. Due to the wall effect the affected concrete cover layer of SIA specimens may have had higher binder content, lower $w / b$ as well as lower effect of the interfacial transitional zone (ITZ) and thus a lower permeability than that of RILEM specimens.

\subsection{Overall comparison}

In Figure 3 the performance values of ECO are compared with those of REF. This shows workability (spread,10), 1-daystrength, 28-day-strength, water penetration depth, open porosity, air permeability tested by SIA- and RILEM-method, sorption coefficient as well as environmental impact GWP and PEt. Flowable consistency of the fresh concrete directly after mixing was achieved for both mixes (spread_10 equal to $52 \pm 2 \mathrm{~cm}$ ). The $1 \mathrm{~d}$-strength of ECO was significantly higher than that of REF, because of accelerated strength development by the effect of MF and the mix design concept. The $28 \mathrm{~d}$ strength of both was equal. The aim of improving ecological performance while keeping workability and $28 \mathrm{~d}$ strength at the level of the reference concrete was achieved. GWP of ECO was reduced up to $36 \%$ and PEt up to $19 \%$ compared to REF.

The durability parameters open porosity, RILEM air permeability and sorption coefficient show a better performance (i.e. lower values) for ECO compared with REF. On the other hand, in the context of water penetration and SIA air permeability, ECO achieved higher values than REF. With respect to their scatter, the performance is in the same range. However, the significant difference of the resulting permeability coefficients $\mathrm{K}_{\text {SIA }}$ and $\mathrm{K}_{\text {RILEM }}$ must be mentioned as discussed above.

Table 4. Tested air permeability parameters

\begin{tabular}{|c|c|c|c|c|c|c|c|c|}
\hline \multirow[t]{3}{*}{ method } & \multirow[t]{3}{*}{ series } & \multirow[t]{3}{*}{ sample } & $\begin{array}{l}\text { affected } \\
\text { cover depth }\end{array}$ & $\begin{array}{l}\text { air perm. } \\
\text { coefficient }\end{array}$ & $\begin{array}{l}\text { air perm. } \\
\text { geometric mean }\end{array}$ & $\begin{array}{l}\text { standard deviation } \\
\text { of } \log (\mathrm{K})\end{array}$ & $\begin{array}{l}\text { standard } \\
\text { deviation factor }\end{array}$ & $\begin{array}{l}\text { range of } \mathrm{K} \\
\text { (scatter) }\end{array}$ \\
\hline & & & $\mathbf{L}$ & $\mathrm{K}_{\text {(SIA or RIL) }}$ & $\mathbf{K}_{\text {(SIA or RIL) }}$ & sd $\log (K)$ & SDF & $\mathrm{K}_{\text {(SIA or RIL) }}$ \\
\hline & & & $\mathrm{mm}$ & $10^{-16} \mathrm{~m}^{2}$ & $10^{-16} \mathrm{~m}^{2}$ & & & $10^{-16} \mathrm{~m}^{2}$ \\
\hline \multirow{9}{*}{ SIA } & \multirow{3}{*}{ REF_G } & REF_G1 & 9 & 0.036 & \multirow{6}{*}{0.022} & \multirow{6}{*}{0.256} & \multirow{6}{*}{1.802} & \multirow{6}{*}{$\begin{array}{l}0.012- \\
0.039\end{array}$} \\
\hline & & REF_G2 & 5 & 0.010 & & & & \\
\hline & & REF_G3 & 5 & 0.010 & & & & \\
\hline & \multirow{3}{*}{ REF_Z } & REF_Z1 & 9 & 0.032 & & & & \\
\hline & & REF_Z2 & 8 & 0.027 & & & & \\
\hline & & REF_Z3 & 9 & 0.031 & & & & \\
\hline & \multirow{3}{*}{ ECO } & ECO_1 & 9 & 0.033 & \multirow{3}{*}{0.030} & \multirow{3}{*}{0.078} & \multirow{3}{*}{1.196} & \multirow{3}{*}{$\begin{array}{l}0.025- \\
0.036\end{array}$} \\
\hline & & ECO_2 & 9 & 0.035 & & & & \\
\hline & & ECO_3 & 8 & 0.025 & & & & \\
\hline \multirow{4}{*}{ RILEM } & \multirow{2}{*}{ REF } & REF_1R & - & 1.219 & \multirow{2}{*}{1.011} & \multirow{2}{*}{0.115} & \multirow{2}{*}{1.302} & 0.777 - \\
\hline & & REF_2R & - & 0.839 & & & & 1.317 \\
\hline & \multirow{2}{*}{ ECO } & ECO_1R & - & 0.256 & \multirow{2}{*}{0.262} & \multirow{2}{*}{0.014} & \multirow{2}{*}{1.033} & $0.254-$ \\
\hline & & ECO_2R & - & 0.268 & & & & 0.271 \\
\hline
\end{tabular}

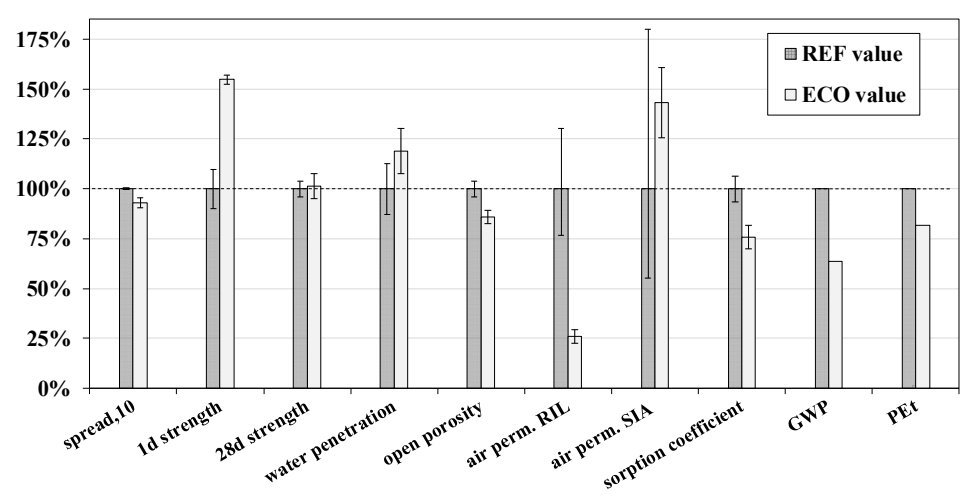

Figure 5. Normalized comparison of all investigated parameters.

\section{Conclusions and Outlook}

In this study eco-concrete (ECO) and in particular its paste was designed by a combined filler concept with the aim of optimizing its performance in respect to functionality, environmental impact and durability. The PC content of ECO was below the requirements set by the current "descriptive" European standards while w/c-ratio exceeded such limits. Subsequently the performance of the developed ecoconcrete was evaluated in terms of workability, strength and 
durability indicators versus a standard reference concrete (REF). While the functional performance of ECO in terms of workability and strength was at least equivalent to REF, the environmental impact was substantially reduced (GWP -36\% and PEt -19\%). Durability indicators - open porosity, water penetration depth, sorption coefficient and air permeability overall show nearly equivalent performance. The resulting air permeability coefficients tested by a bubble tester in accordance with RILEM TC 116-PCD [18], however, showed significant differences compared with coefficients tested by PermeaTORR AC device in accordance with SIA 262/1:2013 [15]. This can mainly be attributed to different moisture content due to preconditioning, but also to the different pressure applied and the affected concrete-layer thickness of the two methods.

Further investigations on a larger number of specimens and concrete-mix variations are pending with the aim of deriving clear relationships between mix parameters of eco-concretes and durability indicators. In addition the significance of durability indicators such as air permeability and their testing methods for the resistance of concrete in the context of different exposure classes (such as carbonation and chloride ingress) is to be investigated in more detail, especially for ecoefficient, clinker-reduced concrete.

\section{Acknowledgements}

The authors thank Prof. Dr. Ivan Gabrijel, University of Zagreb and Dr. Roberto Torrent for providing measurement data, for performing tests and for helpful discussion.

\section{References}

[1] E. Gartner, H. Hirao, A review of alternative approaches to the reduction of $\mathrm{CO}_{2}$ emissions associated with the manufacture of the binder phase in concrete, Cem Concr Res (2015) 78: 126-142. https://doi.org/10.1016/i.cemconres.2015.04.012

[2] M. Glavind et al, Guidelines for green concrete structures, International Federation for Structural Concrete, fib bulletin 67 (2012). https://doi.org/10.35789/fib.BULL.0067

[3] COST Action TU1404, https://www.tu1404.eu/.

[4] H.S. Müller, M. Haist, M. Vogel, Assessment of the sustainability potential of concrete and concrete structures considering their environmental impact, performance and lifetime, Constr Build Mater (2014): 321-337. https://doi.org/10.1016/j.conbuildmat.2014.01.039

[5] T. Proske, S. Hainer, M.Rezvani, C. Graubner, Eco-friendly concretes with reduced water and cement contents - Mix design principles and laboratory tests, Cem Concr Res (2013) 51: 38-46. https://doi.org/10.1016/j.cemconres.2013.04.011

[6] S.A.A.M. Fennis-Huijben, Design of ecological concrete by particle packing optimization. PhD thesis, Delft University of Technology (2010).

[7] J. Juhart, D. Gheorghe, C. Baldermann, G. Fischer, F. Mittermayr, P. Maydl, Durable Eco-Crete in Austria: Materials and Mix Design Methods, Proc. International Symposium - Environmental Friendly Concrete - Eco-Crete (2014), 311-8.

[8] J. Juhart, D. Gheorghe, C. Baldermann, G. Fischer, F.Mittermayr, A new combined filler concept for eco-concrete, Proc. of 14th International Congress on the Chemistry of Cement (2015).

[9] J. Juhart, D. Gheorghe, M. Saade, C. baldermann, A. Passer, F. Mittermayr, Functional and environmental performance optimization of Portland cement-based materials by combined mineral fillers, Cem Con Res (2019) 122: 157-178. https://doi.org/10.1016/j.cemconres.2019.05.001

[10] P. Richard, M. Cheyrezy, Composition of reactive powder concretes, Cem Concr Res (1995) 25:1501-1511. https://doi.org/10.1016/0008-8846(95)00144-2
[11] Marquardt, Determination of the composition of self-compacting concretes on the basis of the water requirements of the constituent materials - presentation of a new mix concept, BFT International (2002) 11: 22-30.

[12] M. Hunger, H.J.H. Brouwers, Flow analysis of water-powder mixtures: Application to specific surface area and shape factor, Cem Concr Compos (2009)31: 39-59. https://doi.org/10.1016/j.cemconcomp.2008.09.010

[13] H. Okamura, K. Ozawa, Mix design for self-compacting concrete, Concrete Library of JSCE (1995).

[14] ONR 23303: 201009 01, Test methods for concrete - National application of testing standards for concrete and its source materials (in German), Austrian Standards (Ed.) (2010).

[15] SIA 262/1:2013, Concrete Structures - Supplementary Specifications (in German), Schweizerischer Ingenieur- und Achitektenverein (Ed.) (2013).

[16] Materials Advanced Services Ltd (Ed.), User manual PermeaTORR, http://www.m-a-s.com.ar.

[17] Testing Bluhm \& Feuerherdt GmbH, User manual (in German), Prüfeinrichtung zur Messung der Luftpermeabilität, https://testing.de/de/2.0331.

[18] RILEM TC 116-PCD, Permeability of Concrete as a Criterion of its Durability. Mater Struct (1999) 32. https://doi.org/10.1007/BF02481511

[19] EcoinventCenter, ecoinvent database v2.2: Swiss Center for LCA (2010).

[20] EFCA, Environmental Product Declaration, Concrete admixtures Plasticizers and Superplasticizers.

[21] ÖNORM B 4710-1:2018, Concrete - Specification, performance, production, use and conformity-Part 1: Rules for the implementation of ÖNORM EN 206 for normal and heavy concrete (in German), Austrian Standards (Ed.) (2018).

[22] B. Lothenbach, K. Scrivener, R. D. Hooton, Supplementary cementitious materials, Cem Concr Res (2011)41: 1244-1256. https://doi.org/10.1016/j.cemconres.2010.12.001

[23] P. Lawrence, M. Cyr, E. Ringot, Mineral admixtures in mortars: Effect of inert materials on short-term hydration, Cem Concr Res (2003) 33: 1939-1947. https://doi.org/10.1016/S0008-8846(03)00183-2

[24] J. Juhart, G.A.David, Baldermann C., Specification of eco-efficient concrete for precast components, part 1 and part 2, CPI - Concrete Plant International N³ \& 4 (2019).

[25] R. Torrent et al., Specification and site control of the permeability of the cover concrete: The Swiss approach, Mater Corros (2012) 63: 1127-1133. https://doi.org/10.1002/maco.201206710

[26] ÖNORM EN ISO 10456:2010, Building materials and products Hygrothermal properties - Tabulated design values and procedures for determining declared and design thermal values (ISO 10456:2007 + Cor. 1:2009); (in German), Austrian Standards (Ed.) (2010).

[27] R. Torrent et al., Suitability of impedance surface moisture meter to complement air permeability tests, RILEM Pro 128, Proc. RILEM International Conference on Sustainable Materials, Systems and Structures, March 2019, Rovinj, Croatia (2019). 